\title{
Diversity from within: The Impact of Cultural Variables on Emotion Expressivity in Singapore
}

\author{
Carolyn M. Hurley ${ }^{1}$, Wen Jing Teo ${ }^{1}$, Janell Kwok ${ }^{1}$, Tessa Seet ${ }^{1}$, Erika Peralta ${ }^{1} \&$ Shuang Yu Chia ${ }^{1}$ \\ ${ }^{1}$ University at Buffalo, the State University of New York, USA \\ Correspondence: Carolyn Hurley, Department of Communication, University at Buffalo Undergraduate Degree \\ programs in Singapore, 461 Clementi Rd, 599491, Singapore. Tel: 1-65-6248-9152. E-mail: \\ churley5@buffalo.edu
}

Received: May 23, 2016

Accepted: June 14, $2016 \quad$ Online Published: June 26, 2016

doi:10.5539/ijps.v8n3p50

URL: http://dx.doi.org/10.5539/ijps.v8n3p50

\begin{abstract}
Culture is intrinsically linked with emotion expression, as culture provides rules regarding how to manage emotions when they occur. Thus far, existing literature has extensively compared norms for emotional expression and suppression, revealing significant differences among culturally distinct but also geographically distant groups (e.g., "collectivistic" Chinese versus "individualistic" U.S. Americans). The present study examines the impact of cultural diversity within Singapore, a heterogeneous Asian nation of 5.4 million residents. Using an expression suppression paradigm, eighty-three participants viewed emotion eliciting video clips and their expressions were analyzed according to the Emotion Facial Action Coding System (EmFACS, Ekman, Irwin, \& Rosenberg, 1994) for signs of happiness and disgust. Participants tasked to manage their expression were successful; however cultural indicators such as ethnicity, collectivism, and concern for face affected expressivity under both suppression and natural expression conditions. These results emphasize the importance of exploring culture within national boundaries, as multiple cultural factors (e.g., ethnic groupings, values, and face) influenced expression.
\end{abstract}

Keywords: culture, emotion, facial expression, suppression

\section{Introduction}

\subsection{Emotional Expression and Culture}

The expression of emotions is an important experience that is influenced by culture. Although emotions produce consistent behavioral displays in individuals from around the world (Ekman, 2003), cultural display rules (Ekman \& Friesen, 1969, 1975) do dictate how to manage emotions once they are triggered. These display rules are learned through socialization, intrinsically known by cultural members, and provide powerful guides for interpersonal interactions. Understanding a culture's display rules is an important component of interpersonal and emotional competence.

However, defining a culture in which to study display rules can be tricky (Baldwin, Faulkner, Hecht, \& Lindsley, 2006), which leads many scholars to rely on national boundaries when examining expression cross-culturally. Cross-cultural research suggests that individuals from large Asian countries-such as China, Japan, and South Korea-are generally less expressive than their U.S. American counterparts, have more rules for managing expression, and are more experienced at suppressing emotions that are deemed disadvantageous to the group (Butler, Lee, \& Gross, 2007; Safdar et al., 2009). These display rules provide guidelines for expressive behavior and reflect the values of the larger, but sometimes heterogeneous, culture.

The present study examines emotion management within a unique cultural context. Given that norms for expression are linked to differences in values, not geography (Matsumoto et al., 2008), we posit that equating culture with national boundaries may construct artificial classifications that obscure the myriad of cultural patterns affecting daily interaction within one nation. The current study examines participants from Singapore: a small island nation with a strong national identity despite comprising a multiethnic population. Within this small population we posit that indicators such as ethnic identity, collectivist value and individual preference for face management can provide the basis for cultural differences in emotion expression as well as suppression ability. 
Understanding differences in cultural suppression may provide insight to wider issues in interpersonal communication and individual well-being. Given that suppression appears characteristic of "eastern" cultures, it is important to take a closer look within these groupings to identify more specific correlates to suppressive ability, rather than label it a regional phenomenon. The following sections describe the background of emotion expression, suppression, and cultural dimensions which informed our examination.

\subsection{Managing Emotional Expression}

\subsubsection{Culture and Expression}

Early research examining isolated cultures established that a core number of basic human emotions- happiness, sadness, disgust, anger, fear and surprise — shared universal expressions across cultures (Ekman \& Friesen, 1971; Ekman, Sorenson, \& Friesen, 1969). This universal agreement in expression suggests that emotional expressions are genetically determined, and biology is largely responsible for establishing which facial movements are associated with certain emotions (Ekman, 1977). As social creatures we have evolved to display facial expressions of our emotions to communicate danger, signal distress, and convey approachability (Frijda, 1986). Neuroanatomical studies support that when an individual experiences an emotion, the subcortical area of the brain triggers involuntary expressions of emotion; although people also maintain voluntary control of expression through the cortical motor strip (Meihkle, 1973; Myers, 1976; Tschiassny, 1953). This allows individuals to engage in expressive management by amplifying, de-amplifying, masking, neutralizing, qualifying, or simulating emotions regardless of whether they are experiencing an emotion (Ekman \& Friesen, 1969, 1975).

While research has verified cross-cultural agreement in the identification and expression of facial expressions of emotions, the management of facial expressions of emotion appears dependent on culture. According to Matsumoto et al. (2008), "cultures create rules, guidelines, and norms concerning emotion regulation because emotions serve as primary motivators of behavior and have important social functions" (p. 927). As our society advances, we have learned to exert more facial control to cover, mask, or suppress our expressions as a function of daily life and the facilitation of comfortable social interaction (Gross, 2002).

For example, our choice to manage or suppress a negative emotion-like disgust at a boss's poor dining etiquette over a business lunch - might reflect a culture's emphasis on respecting authority or maintaining interpersonal harmony. Cultural display rules reflect core values such as autonomy, group harmony, respect, hierarchy, and egalitarianism (Matsumoto et al., 2008), which can conflict between cultures. Hence, a culture's display rules learnt through socialization can lead to intercultural discord, as what seems second-nature to its members may be unknown or "strange" to outsiders. This suggests a culture's underlying value dimensions, rather than geographic discriminators, are important to the examination of emotional displays.

\subsubsection{Emotion Suppression}

Individuals manage their emotions through processes of reappraisal and suppression (Gross, 1998). Reappraisal involves reinterpreting an emotion-eliciting stimulus whereas suppression includes controlling, masking or neutralizing the emotional behavior (Gross, 1998; Gross \& John, 2003; Gross \& Levenson, 1993). We have chosen to examine suppression, as it tends to occur when embeddedness, collectivism, hierarchy, and power differences are valued, whereas reappraisal has few cultural ties (Matsumoto et al., 2008). Further, emotion suppression and cultural display rules are connected; as display rules provide the guidelines for when an individual should engage in behaviors such as emotional restraint.

At the social level, emotion suppression may be seen as advantageous, as individuals who value suppression are more sensitive to others and tend to adapt their behavior based on the context or interactant (Butler et al., 2007). However, at an individual level suppression has been related to negative outcomes such as decreased empathy, stigmatizing attitudes, reluctance to help (Lebowitz \& Dovidio, 2015), compromised cognitive performance (Franchow \& Suchy, 2015), and lower citizen happiness (Matsumoto et al., 2008). While suppression is not always the most effective emotion management strategy, having the ability to suppress allows individuals greater flexibility and control over their communication.

Emotion suppression can be examined through self-report and experimentation; depending on whether the aim is to understand the context or rules for suppression or the behavioral ability to suppress. The current study mimics emotion suppression experiments, in which participants are instructed to act as though they feel nothing despite watching emotion eliciting videos (Gross, 1998; Gross \& Levenson, 1993). Some studies also asked participants to mask their true feelings by feigning a different emotion (Porter \& ten Brinke, 2008). All these studies are similar in that they require participants to consciously monitor and restrain their spontaneously occurring 
expressive behavior. The studies are also similar in their findings - that basic instruction to suppress or conceal their emotions reduced (but did not eliminate completely) the emotional expressions of the participants.

Our aim is to use the suppression paradigm as the basis of our examination of the cultural influence on suppression ability in Singapore. Given the biological nature of emotional displays, we predict that participants in Singapore will display similar expressive patterns as seen in foundational research (e.g., Gross \& Levenson, 1993). Specifically:

H1. Participants in the emotion suppression (experimental) condition will display fewer and less intense emotional expressions than participants in the control condition.

Although people have the ability to mask facial movements, studies suggest that certain expressions may be easier to conceal than others (e.g., Hurley \& Frank, 2011; Porter \& ten Brinke, 2008). Given the wide array of expressions we are able to display, we have chosen to focus on two emotional expressions: disgust - a negative emotion, and happiness - a positive emotion. These emotions are more easily elicited in the laboratory then others (e.g., fear, anger, see Rottenberg, Ray, \& Gross, 2007) and hence should provide a good place to start our examination. Further the comparison of a positive and negative valence emotion provides insight into a range of cultural rules and ability related to emotion suppression.

\subsection{Measures of Culture}

\subsubsection{The Singapore Context}

Singapore provides an excellent setting for examining cultural diversity within Asia. Singapore is a nation of only five million residents, yet multiculturalism is part of its national identity (Ministry of Culture, Community and Youth, 2015). Singapore has four national languages and holds public holidays for multiple religions (e.g., Christmas, Hari Raya, and Vesak Day) and multiple New Year celebrations (e.g., New Year's Day, Deepavali, and Lunar New Year). From young, citizens celebrate "Racial Harmony Day" (Ministry of Education, 2014) which promotes understanding and appreciation of cultural diversity. This illustrates the promotion of diversity within this small Asian nation.

Ethnicity has always played an important role in Singaporean identity, as residents are categorized into explicit and organized ethnic groupings that dictate their opportunities and route within the education system, self-help organizations, public housing ownership and electoral representation in the Group Representation Constituency (GRC) (Ackermann, 1997; Chan, Haines, \& Lee, 2014). Since it gained independence in 1965, the Singapore government has adopted an "ethnically neutral" approach (Ackermann, 1997) which ensures social cohesion by officially embracing multiculturalism in its policymaking decisions. The government believed that by delineating cultures based on ethnicity, “... it [would] set about not only enhancing ethnicity as a primary social identification but extend this principle to making ethnicity the main form of sociocultural classification" (Clammer, 1985, p. 142). As a consequence of this constant categorization, each Singaporean is deeply aware of his or her ethnic classification. These structured categories are known as the CMIO model (Siddique, 1989).

The CMIO model refers to a system that categorizes Singaporeans into four main ethnic groups-labeled as Chinese, Malay, Indian, and Others (Siddique, 1989). One of the most significant impacts of the CMIO model is on Singapore's education system. The bilingualism policy requires students to learn the English language and their mother tongue based on parents' ethnicity. This program was integrated into the education system to help Singaporeans acquire and maintain their respective cultural history and values through their mother tongue whilst sharing a national identity (Chua, 2009). Its impact can be observed in a comparison of Chinese and English speaking students which found that those students who preferred speaking in their mother tongue were more acculturated with traditional Chinese values (Chang, Wong, \& Koh, 2003). The bilingual education system works alongside familial nurturing to engender different cultural values learned by each ethnic group. Consequently, the CMIO model has served as an indicator of cultural influence for several intergroup comparisons in Singapore context (e.g. Mak, Ho, Chua, \& Ho, 2015; Mariapun, Yip, Taib, \& Teo, 2015; Ng, Leong, Chiam, \& Kua, 2010). Thus, we chose to utilize the CMIO model to begin basic comparisons of culture within Singapore.

In 2014, Singapore's ethnic composition of the resident population included $74.3 \%$ Chinese, $13.4 \%$ Malays, 9.1\% Indians, and 3.3\% of "Other" ethnicities (Singapore Department of Statistics, 2015). While we undertake several measures of culture, our first step is to examine the four major ethnic groups within Singapore. Singapore provides a unique context in which grouping by ethnicity is frequent and encouraged and may reflect differences in nonverbal behavior. We employ the following research question as this examination of ethnicity in Singapore 
is exploratory and the impact of administratively encouraged division on identity and norms is unknown. Therefore:

RQ1: Are there differences in emotion expressivity and suppressive capacity between different ethnic groups within Singapore?

\subsubsection{Cultural Values}

\section{(a) Individualism-collectivism}

Examining culture as a multi-dimensional concept, social scientists typically use value dimensions to understand cultural differences in communication (Hoftstede, 1980; Ting-Toomey, 2010). One of the most heavily researched cultural dimensions discussing the role of group harmony is individualism-collectivism (Kirkman, Lowe, \& Gibson, 2006). According to Hofstede (1980), individualism-collectivism evaluates the degree to which a culture values an individual's needs as compared to the in-group's interests. Individualists place greater value on self, whereas collectivists routinely consider others' needs and consult others when making a decision. Generally, most western countries are considered to be individualistic, and many eastern countries are considered to be collectivistic (Hofstede, 1980). While Singapore has been characterized as a collectivist nation in previous research (e.g., Galovan et al., 2010), categorizing all Singaporeans as collectivist would disregard the point that collectivism is a reflection of values of a culture, not geography. Therefore, this study considers individualism-collectivism as cultural component measured individually on a continuum (Cai \& Fink, 2002; Hui \& Triandis, 1986).

It is well established that emotion control is highly valued in Asian cultures. Many researchers attribute this to the importance placed on maintaining group harmony. A study of 23 countries revealed that cultures that valued embeddedness, hierarchy, and were future-oriented reported engaging in greater emotion suppression than cultures valuing individualism, egalitarianism, and affective autonomy (Matsumoto et al., 2008). A similar study recording impressions of Taiwanese Chinese and European Americans indicated that Taiwanese Chinese engage in more suppression to maintain interpersonal harmony compared to their European American counterparts (Wei, $\mathrm{Su}$, Carrera, \& Lin, 2013). These studies support the general consensus that Asian cultures believe that self-expression may 'disturb social harmony' leading to constant engagement in emotion regulation (Markus \& Kitayama, 1991).

Individualism-collectivism is related to emotion expression and suppression. In general, individualistic cultures promote primacy of individual needs, and individuals are encouraged to be authentic and open with their expression (Butler et al., 2007). Collectivist cultures value emotion suppression (Matsumoto et al., 2008), generally have more rules for expression management, and are more sensitive to others around them when expressing emotion, especially negative emotions (Butler et al., 2007; Safdar et al., 2009; Wei et al., 2013). Thus, extended to expression of positive and negative emotions we predict:

H2. Collectivism is negatively related to negative emotion expression (fewer expressions of disgust) and positively related to positive emotion expression (more expressions of happiness).

\section{(b) Face preferences}

The concept of face is related to the individualism-collectivism dimension (Ting-Toomey, 1988). Face is a claimed public image or concern over our impression management, concerned with garnering liking and respect (Goffman, 1959). Face-negotiation theory (Ting-Toomey \& Kurogi, 1998) places this variable in an interactive context, positing that understanding both our own face and others' face can aid members in maintaining harmony with others. In societies influenced by Chinese culture, face is considered in every interaction (Qi, 2011).

While most often cited in intercultural conflict studies, face negotiation theory may provide insight into individual differences in emotion expression and capacity for suppression. Although the current paradigm does not mimic a routine interpersonal interaction, there is an interactive component as the participant is conscious of being monitored by another party. In this experiment, the control group is advised to "express naturally as if they were at home and alone", whereas the experimental group is told to manage their emotions. Therefore all participants have some awareness that they are being monitored.

The concept of face includes a concern with one's own image, or self-face, and a concern for another individual's image, or other-face (Ting-Toomey, 1988). Individuals concerned with self-face are concerned with how their expression affects their representation, and a display of emotion outside the norm may lead to a loss of face and hurt their reputation. Given that negative emotions restraint is valued in many Asian cultures (e.g., Louie, Oh, \& Lau, 2013; Tsai, Knutson, \& Fung, 2006), we would expect to see more positive emotional 
expression and less frequent negative emotion expression from these individuals, regardless of situational condition. Therefore we predict:

$H 3$. Concern for self-face is positively related to expressions of happiness and negatively related to expressions of disgust, regardless of suppression condition.

Concern for other-face also guides emotional expression, as these individuals may choose to display emotions based on the feedback given by their partner. These individuals may routinely repress their individual desires and behaviors to sustain interpersonal harmony. In the current study we ask participants to view emotionally eliciting videos and either display their expression "naturally" or suppress their facial behavior. While this task is performed alone, participants still engage with an Experimenter whom they might regard as a person of status. Thus we predict that individuals with a high other-face concern to be more sensitive in following their experimenter's directions. Specifically,

H4. Other-face is positively related to emotion expression (more expressions of both happiness and disgust) in the control condition and negatively related to emotion expression (fewer expressions of both happiness and disgust) in the suppression condition.

The current study aims to examine cultural differences in emotion suppression among different ethnic groups in Singapore, as well as identify the impact of values such as collectivism and face-negotiation. Despite vast research comparing European Americans with other cultural groups (e.g., Butler et al., 2007; Matsumoto et al., 2008; Soto, Perez, Kim, Lee, \& Minnick, 2011; Wei et al., 2013), there is paucity in research comparing value-based cultural differences in emotion suppression in Singapore. The present study aims to address this gap in information.

\section{Methods}

\subsection{Participants}

Eighty-five students participated in a study about emotion expression with prior disclosure about the videotaping procedures. Two participants were removed from the analyses due to unusable video footage (Note 1), resulting in eight-three participants ( $75 \%$ female) included for analyses. Participants were on average 21.57 years old ( $S D$ $=1.93)$ and self-identified their ethnic background as Chinese $(30.1 \%)$, Indian $(25.3 \%)$, Malay $(26.5 \%)$, or "Other" (18.1\%). Participants were randomly assigned to the control (13 Chinese, 10 Indian, 10 Malay, 8 "Other") or experimental (12 Chinese, 11 Indian, 12 Malay, 7 "Other") condition.

\subsection{Measures}

The effect of culture on suppression was evaluated using measures of ethnic background, collectivism, concern for self-face, and concern for other-face. Participants self-identified their ethnic background by choosing one of Singapore's four main ethnic groups. Few studies have used formal scales to measure face in Singapore, so we used Oetzel and Ting-Toomey's (2003) measure to evaluate the self-face (4-items, $\alpha=.800)$ and other-face dimensions (6-items, $\alpha=.571)$. Cross-cultural validation was recently confirmed for a subset of the utilized scale (Fletcher et al., 2014). Face-concern items were evaluated on a 1 (strongly disagree) to 5 (strongly agree) response scale with higher scores representing greater concern for self or other face. We measured collectivism with the 11-item INDCOL scale (Hui \& Triandis, 1986) as adapted by Cai and Fink (2002) $(\alpha=.74)$, with higher scores representing greater collectivism. Collectivism items were evaluated on a 1 (strongly disagree) through 5 (strongly agree) response scale with some items reverse coded.

\subsection{Stimulus Video Clips and Pilot Study}

While emotion suppression can be manipulated using validated image sets (e.g., IAPS, Lang, Bradley, \& Cuthbert, 1999), we chose to trigger emotional displays using novel, dynamic stimuli. We propose that the use of dynamic stimuli, 1) contains greater ecological validity, and 2) may trigger greater variation in emotional displays (given the stimuli are longer in length-IAPS images are typically shown for only 4 seconds, Murata, Moser, \& Kitayama, 2013).

We identified 26 short video clips (30-180 seconds) from youtube.com, local news broadcasts, television shows, and movies with expected potential to induce the seven basic emotions (anger, contempt, disgust, fear, happiness, sadness, and surprise). We carefully considered appropriateness and local context while choosing each video clip, with effort to choose clips that were relevant (e.g., a clip of a Singaporean student berating his teacher), and emotionally arousing but not emotionally disturbing (e.g., use of a horror movie trailer versus a murder scene from the horror movie) to the target population. 
We conducted a pilot study to gather feedback on the emotional eliciting nature of the video clips. These video clips were organized into two 13-clip video sets (approximately 25-minutes each) for testing. Forty-seven students viewed and rated the emotionality of each video clip within the two video sets by indicating their felt emotion on a Likert scale (with $0=$ no felt emotion and $10=$ strongly felt emotion) for 15 emotion terms (e.g., anger, disdain, delight, fear). We chose eleven video clips based on the highest average ratings provided by participants for the seven basic emotions. Most video clips rated an average of 7 (of 10) or above for a target emotion (e.g., disgust, happiness). However, two additional video clips rating 6/10 were included for fear and anger, as these emotions were more difficult to induce through our experimental procedures. Video clips were ordered to begin and end with positive emotions; to set participants at ease and then relax them at the end of the experiment (see Appendix A). The target clips for the current study were positioned at number 4 (disgust), 5 (happiness), 7 (disgust), and 9 (happiness) to examine participants' expressive behaviors within a broader experience of emotions.

\subsection{Main Study Procedure}

Participants were recruited via an online portal and participated alone. Upon arrival to the designated conference room, participants were randomly assigned to either control (natural expression) or experimental (suppression) group. After obtaining informed consent, participants completed a questionnaire gathering demographic information as well as ratings for collectivism and face preferences. Once participants received instructions, they proceeded to view the 20-minute video comprised of eleven video clips (Appendix A) intended to stimulate the basic emotions of anger, contempt, disgust, fear, happiness, sadness, and surprise. During the video task, one experimenter remained in the room, seated away from the participant and facing a different direction, to remain accessible for questions or technical problems yet provide space to the participant. We recorded participants' facial expressions using a Panasonic Lumix DMC-TZ5 9.0 megapixel camera in standard definition. At the end of the video task, participants discussed their experience in the experiment, were debriefed, compensated, and dismissed. Participants received SGD10 for their participation.

The only difference between the control and suppression conditions were the instructions provided to participants prior to the video task. In the control condition, participants were instructed to watch the clips as if in a natural setting, specifically "We'd like you to watch these videos as you would if you were at home and relaxed." In the suppression condition, participants were instructed to suppress their facial expressions, specifically, "As you watch these videos we'd like you to try to suppress or eliminate any emotional expressions you have. Specifically, try to keep a poker or neutral expression during the length of this task." Post-task, participants in the suppression condition rated their task as significantly more difficult $(1=$ Very difficult, $7=$ Not difficult at all, $M=5.38, S D=1.70, F(1,81)=27.403, p<.001)$ than participants in the control condition $(M$ $=6.80, S D=0.40$ ).

\subsection{Facial Coding}

The current analysis compares the expression and suppression of one negative emotion (disgust) to one positive emotion (happiness). We chose to compare one positive and one negative emotion, as many cultural factors do influence differences in displaying positive versus negative emotions (e.g., Matsumoto et al., 2008). Further, happiness and disgust were chosen given these emotions are easier to elicit in an experimental setting (Rottenberg et al., 2007). Four of the eleven video clips were analyzed for this study providing 5:57 minutes of codable video.

Participants' facial expressions were recorded and analyzed for the target expressions (disgust-action units 9 or 10 and happiness-action units 6 plus 12) according to the Emotion Facial Action Coding System (EMFACS; Ekman et al., 1994). Frequency, duration, and apex intensity of expressions were coded. Two coders analyzed eight participants (87,543 frames) to assess inter-coder reliability. The two coders matched on 70 of the 91 target expressions identified (inter coder agreement $=.77$ ); the first coder's codes were used for analysis.

\section{Results}

\subsection{Emotion Expressions}

The eighty-three participants produced 622 target expressions over the four video clips (336 happiness, 274 disgust). The descriptive statistics for the expressions displayed during the four video clips are shown in Table 1. 
Table 1. Descriptive statistics of facial expressions

\begin{tabular}{lcccccccc}
\hline & \multicolumn{2}{c}{$\begin{array}{c}\text { Video Clip 1 } \\
\text { (Disgust) }\end{array}$} & \multicolumn{2}{c}{$\begin{array}{c}\text { Video Clip 2 } \\
\text { (Happiness) }\end{array}$} & \multicolumn{2}{c}{$\begin{array}{c}\text { Video Clip 3 } \\
\text { (Disgust) }\end{array}$} & \multicolumn{2}{c}{$\begin{array}{c}\text { Video Clip 4 } \\
\text { (Happiness) }\end{array}$} \\
\cline { 2 - 9 } Variable & $\mathrm{N}$ & $\mathrm{M}(S D)$ & $\mathrm{N}$ & $\mathrm{M}(S D)$ & $\mathrm{N}$ & $\mathrm{M}(S D)$ & $\mathrm{N}$ & $\mathrm{M}(S D)$ \\
\hline Average Frequency & 77 & $1.2(1.86)$ & 83 & $1.5(1.28)$ & 80 & $2.5(3.40)$ & 83 & $2.6(2.42)$ \\
Average No. of Frames & 77 & $229(504)$ & 83 & $431(473)$ & 80 & $572(999)$ & 83 & $596(677)$ \\
Average Intensity & 33 & $2.2(.85)$ & 63 & $2.2(.95)$ & 45 & $2.3(.92)$ & 54 & $2.7(1.00)$ \\
\hline
\end{tabular}

The stimuli elicited fewer negative emotional expressions as compared to positive emotional expressions, which positively skewed the frequency and total frames of disgust expressions across the subjects. During video clip 1, only $42.9 \%$ of participants showed one or more disgust expressions and during video clip 3, 56.3\% of participants showed one or more disgust expressions. During video clip 2, 75.9\% of participants showed one or more happiness expressions, and during video clip 4, 65.1\% of participants showed one or more happiness expressions.

\subsection{Emotion Suppression}

We predicted that participants in the suppression condition would display fewer and less intense emotional expressions than participants in the control condition (H1). An ANOVA was conducted on the total number of expressions (across all four videos) by experimental condition. The ANOVA was significant, $F(1,74)=55.011$, $p<.001, \eta^{2}=.426$, revealing that control participants showed significantly more $(M=12.94, S D=6.7)$ disgust and happiness expressions than suppression participants $(M=3.26, S D=4.6)$. We examined intensity at the level of the video clip for the participants who revealed the target emotions. ANOVAs revealed support for our hypothesis that participants in the suppression condition expressed less intense happiness during video clip 2 ( $M$ $=1.56$, controls, $\left.M=2.61, F(1,61)=24.155, p<.001, \eta^{2}=.284\right)$, and video clip $4(M=1.96$, controls, $M=$ $\left.3.01, F(1,52)=15.715, p<.001, \eta^{2}=.232\right)$. There were no significant differences in terms of intensity of disgust; however, the number of suppression participants showing disgust was about one third of the control sample (Video clip 1: $n=9$ vs. $n=24$; Video clip $3: n=13$ vs. $n=32$ ).

Given the non-normal distribution of expressions at each point in time, we conducted nonparametric tests to further examine the presence of target expression during each of the four video clips. Chi-square tests revealed that participants in the control group expressed significantly more disgust during clip $1\left(\chi^{2}(1)=17.325, p<.001\right)$ and clip $3\left(\chi^{2}(1)=22.994, p<.001\right)$ and happiness during clip $2\left(\chi^{2}(1)=20.778, p<.001\right)$ and clip $4\left(\chi^{2}(1)=\right.$ 27.196, $p<.001$ ), supporting our manipulation of suppression and H1 (Table 2).

Table 2. Proportion of each condition and ethnic group displaying one or more target expressions

\begin{tabular}{llccccc}
\hline \multirow{2}{*}{ Clip } & Target Emotion & Chinese & Malay & Indian & Other & Total \\
\cline { 3 - 6 } & Disgust & $54.5 \%$ & $66.7 \%$ & $66.7 \%$ & $100.0 \%$ & $68.6 \%$ \\
2 & Happiness & $100.0 \%$ & $90.0 \%$ & $100.0 \%$ & $100.0 \%$ & $97.6 \%$ \\
3 & Disgust & $92.3 \%$ & $100.0 \%$ & $66.7 \%$ & $71.4 \%$ & $84.2 \%$ \\
4 & Happiness & $92.3 \%$ & $90.0 \%$ & $100.0 \%$ & $87.5 \%$ & $92.7 \%$ \\
\hline \multirow{2}{*}{ Clip } & & & & Suppression & & \\
\hline 1 & Target Emotion & Chinese & Malay & Indian & Other & Total \\
2 & Disgust & $16.7 \%$ & $33.3 \%$ & $27.3 \%$ & $0.0 \%$ & $21.4 \%$ \\
3 & Happiness & $58.3 \%$ & $66.7 \%$ & $54.5 \%$ & $28.6 \%$ & $54.8 \%$ \\
4 & Disgust & $25.0 \%$ & $33.3 \%$ & $36.4 \%$ & $28.6 \%$ & $31.0 \%$ \\
& Happiness & $41.7 \%$ & $50.0 \%$ & $27.3 \%$ & $28.6 \%$ & $38.1 \%$ \\
\hline
\end{tabular}




\subsection{Cultural Influence}

Our remaining research question and hypotheses explored the effect of cultural variables-ethnic grouping, collectivism, other-face, and self-face-on emotion expressivity. We used Pearson correlation followed by regression analyses to explore the relationships among the cultural variables and expressivity in each experimental condition.

Table 3 reveals the associations between the demographic and cultural factors and the frequency of expressions displayed during the experiment. Ethnic background was dummy coded into two variables (Chinese and Indian) to allow comparisons among the three major ethnic groups (thus, the Malay acted as a reference category). We limited our analyses of participants who reported "Other" ethnicities, as this constituted a small and diverse group. In the control condition, correlations revealed that ethnic background played a significant role such that Chinese participants were associated with fewer negative expressions and fewer overall expressions as compared to Indian and Malay participants together. Collectivism was significantly negatively correlated to disgust expressions, supporting H2. H3 was not supported as no significant relationships emerged between self-face concern and expression. Concern for other face was positively related to disgust expression revealing partial support for H4. Individuals who reported concern with maintaining others' interests and dignity displayed more negative expressions when asked to express freely.

These significant relationships disappeared when participants were asked to suppress their facial expressions. In the suppression condition, demographic and cultural factors were not significantly related to frequency of expression, refuting our hypotheses.

Table 3. Pearson correlations between expression and background characteristics

\begin{tabular}{llccc}
\hline Condition & Variable & Total Expressions & $\begin{array}{c}\text { Total Happiness } \\
\text { Expressions }\end{array}$ & $\begin{array}{c}\text { Total Disgust } \\
\text { Expressions }\end{array}$ \\
\hline Control & Age & -.145 & -.186 & -.050 \\
& Sex & & -.059 \\
& Chinese $^{2}$ & -.100 & -.216 & -.074 \\
& Indian $^{3}$ & $-.444^{*}$ & .098 & $.313^{*}$ \\
& Collectivism & .301 & .262 & $-.350^{*}$ \\
& Other Face & -.212 & .272 & $.356^{*}$ \\
& Self Face & $.383^{*}$ & -.116 & .036 \\
\hline Suppression & Age & -.090 & -.043 & -.253 \\
& Sex & -.171 & -.040 & -.102 \\
& Chinese & & .037 & -.239 \\
& Indian & -.082 & -.218 & -.046 \\
& Collectivism & -.119 & .013 & -.260 \\
& Other Face & -.152 & .273 & .111 \\
& Self Face & -.143 & .114 & .131 \\
\hline
\end{tabular}

Note. ${ }^{*} p<.05 .{ }^{1}$ Sex $(1=$ Female, $2=$ Male $) ;{ }^{2}$ Chinese $(1=$ Chinese, $0=$ Malay or Indian $) ;{ }^{3}$ Indian $(1=$ Indian, 0 $=$ Chinese or Malay).

These variables, along with experimental condition, were entered into a linear regression to predict number of positive, negative, and total expressions during the experiment. As indicated in Table 4, the pattern of findings largely replicated those found in the descriptives. The experimental condition, lower reported collectivism and greater concern for other-face were significant predictors of total number of expressions (Adj $R^{2}=.473, F(2,8$, $58)=8.404, p<.001)$. The experimental condition and greater concern for other-face were significant predictors of number of positive expressions (Adj $\left.R^{2}=.395, F(8,64)=6.879, p<.001\right)$. The most cultural factors contributed to frequency of negative expressions, explaining $40.4 \%$ of the variance, $F(8,58)=6.595, p>.001$. 
Identifying as Chinese, reporting greater collectivism, less concern for other-face, in addition to the suppression condition predicted fewer expressions of disgust.

Table 4. Multiple regression of expressions on individual predictors

\begin{tabular}{|c|c|c|c|c|c|c|}
\hline \multirow[t]{2}{*}{ Predictor } & \multicolumn{2}{|c|}{ Number of Total Expressions } & \multicolumn{2}{|c|}{$\begin{array}{l}\text { Number of Happiness } \\
\text { Expressions }\end{array}$} & \multicolumn{2}{|c|}{$\begin{array}{l}\text { Number of Disgust } \\
\text { Expressions }\end{array}$} \\
\hline & Unstd $b(95 \% C I)$ & $p$ & Unstd $b(95 \% C I)$ & $p$ & Unstd $b(95 \% C I)$ & $p$ \\
\hline Suppression $^{1}$ & $\begin{array}{c}-98.749(-11.501, \\
-5.997)\end{array}$ & .000 & $\begin{array}{c}-3.791(-5.008 \\
-2.574)\end{array}$ & .000 & $\begin{array}{c}-4.702(-6.719, \\
-2.684)\end{array}$ & .000 \\
\hline Age & $-.156(-.940, .628)$ & .691 & $-.151(-.504, .202)$ & .396 & $.067(-.508, .642)$ & .815 \\
\hline $\operatorname{Sex}^{2}$ & $1.009(-4.638,2.619)$ & .580 & $2.47(-1.435,1.929)$ & .770 & $-1.293(-3.953,1.368)$ & .335 \\
\hline Chinese $^{3}$ & $-3.384(-6.852, .084)$ & .056 & $-.029(-1.590,1.532)$ & .970 & $-3.234(-5.777,-.692)$ & .014 \\
\hline Indian $^{4}$ & $-.253(-3.633,3.127)$ & .881 & $-.518(-2.035, .999)$ & .498 & $.588(-1.890,3.066)$ & .637 \\
\hline Collectivism & $-.188(-.356,-.020)$ & .029 & $.038(-.038, .114)$ & .324 & $-.217(-.340,-.094)$ & .001 \\
\hline Other Face & $.869(.245,1.492)$ & .007 & $.325(.052, .598)$ & .020 & $.555(.098,1.012)$ & .018 \\
\hline Self Face & $-.171(-.672, .330)$ & .497 & $-.022(-.249, .204)$ & .844 & $-.127(-.494, .241)$ & .492 \\
\hline
\end{tabular}

Note. ${ }^{1}$ Suppression $(0=$ Control, $1=$ Suppression $) ;{ }^{2} \operatorname{Sex}(1=$ Female, $2=$ Male $) ;{ }^{3}$ Chinese $(1=$ Chinese, $0=$ Malay or Indian); ${ }^{4}$ Indian $(1=$ Indian, $0=$ Chinese or Malay $)$.

\section{Discussion}

This study examined the facial expressiveness and suppression capacity of ethnically diverse Asian college students within Singapore. As predicted individuals instructed to suppress their expressions showed fewer and less intense expressions of disgust and happiness overall. These results were consistent with established literature on emotion suppression (e.g., Gross, 1998; Gross \& Levenson, 1993; Schmeichel, Volokhov, \& Demaree, 2008). Furthermore, these results mimic previous findings that while instructions to suppress expressions reduced overall expressivity, many participants were unable to eliminate their expressions completely. In this study, $21-55 \%$ (see Table 2) of participants instructed to suppress revealed at least one target expression during each video clip.

While participants from all ethnic groups engaged in suppression on command, different patterns emerged based on ethnicity and valence of emotion. These differences were only uncovered when positive and negative emotion expressions were examined separately, suggesting specific display rules based on type of emotion. During the disgust-eliciting video clips Chinese participants displayed fewer disgust expressions as compared to the other groups. This suggests that the ethnic identities defined in Singapore's policies appeared to reflect real cultural differences in management of expression.

Ethnic based differences also appeared in the natural expression condition where identifying as Chinese was negatively related to overall expressivity, driven by significantly fewer expressions of negative emotion. This lesser expressiveness demonstrated by Chinese participants is consistent with Confucian values of emotional restraint, self-control, and discipline (Chen \& Swartzman, 2001), which have been promoted in State sponsored curriculum and advertising (Ackermann, 1997). If a cultural being is continually reinforced to manage his or her emotional display, it will most likely become second nature to him or her to regulate emotion expressions. Other ethnic based explanations suggested by Rao, McHale and Pearson (2003) include that Indian mothers tend to prioritize emotional expression than Chinese mothers. Such differences in child rearing practices may reflect 
differences in socialization goals and explain why Chinese participants expressed less than their Indian and Malay counterparts.

As expressive display rules reflect the values of a culture, our data suggests that ethnic grouping is a viable measure of culture in Singapore. This may be linked to Singapore's educational policies and racial harmony regulations that reinforce each resident's racial identification and group membership, and provide benefits based on those classifications. Singapore's practice of reinforcing ethnic identifies through its bilingualism policy and religious celebrations (Ackermann, 1997) may have resulted in a greater perpetuation of ethnic group identity and consequently emotion display rules. This suggests that within Singapore, grouping via nationality may be inadequate for understanding emotional expression, as ethnic identities may more strongly influence the values driving emotional expression and suppression then the Singaporean identity. While these ethnic identities may be unique to Singapore, the presence of cultural differences within one nation should be acknowledged in future research.

Our value-based analyses of culture revealed that collectivism was related to expressivity independent of ethnicity, but type of emotion affected the relationship. Our hypothesis (2) was partially supported as individuals reporting more collectivism revealed less negative emotion, however no relationship to positive emotion was found. This highlights the cultural display rule that while positive emotion is viewed as a constructive emotion regardless of culture; within collective in-groups negative emotions like disgust are considered destructive and should be suppressed (Markus \& Kitayama, 1991; Matsumoto, Takeuchi, Andayani, Kouznetsova, \& Krupp, 1998). This norm appeared to affect negative expressivity overall as collectivism predicted fewer disgust expressions, even when controlling for suppression condition. Collectivism may discourage offending people, and emotions such as disgust can potentially do so when interacting with others. Happiness is seen as a beneficial emotion so individuals may not see a need to suppress it.

Our hypotheses $(3 \& 4)$ examining face-concern were only partially supported. This variable is distinct from collectivism, and suggests that relationship level factors also affect expressivity, and that a concern for a relationship increases our likeliness to share emotions with others, regardless of age, sex, or ethnic background. However, we exercise caution when interpreting the interesting relationships found among other-face and expression, as the other-face measured showed weak reliability in this sample. Research is only recently examining the cross-cultural equivalence of face-negotiation scales (e.g., Fletcher et al., 2014), and while preliminary studies provide some cross-cultural validation they are still limited in scope. Perhaps asking questions such as, In my relationships, maintaining peace in my interactions is important to me, measures an accommodating or agreeable trait rather than concern for another person's poise. While participants were examined alone, the positive correlation found between expression and other-face in the control condition queries whether participants showed more expression to oblige the experimenter. Further examination of face in a Singapore context a further investigation is warranted.

Our predicted relationships for self-face were not realized and this may be due the fact that sample produced higher means on self-face ( $M=13.98,4-20$ point scale). We still believe that concern for self-face could be valuable for understanding emotion suppression; however, it might be better suited for suppression within a face-to-face setting where individuals are more greatly incentivized to protect themselves. In this study, participants were motivated by the compensation of SGD10 for completion of the experiment but there were none of the social consequences or sanctions that are naturally embedded in conversation. It's likely that real life creates stronger motivations to eliminate unwanted emotional displays (although this may come with greater challenges). These findings should be examined in conversational conditions to see how the roles of conversational partner affect the emotional display of a person valuing other and self-face.

The extension of this work to natural interaction is essential for understanding the social and communicative effects of emotion management. While several participants were successful at inhibiting their emotion expressions, this management resulted in other behaviors that appeared unnatural from observation. Our observations revealed that some participants showed success by essentially shutting down all nonverbal behaviors-sitting completely still and unblinking at the computer screen. While this strategy helped them to succeed in the assigned task, it is less useful for suppression within an interpersonal context. Naturally, we show our distaste for negative emotion by turning away from it, avoiding, etc. If we need to suppress or avoid signs of our emotional experience then our body, gaze, or other kinesic movements may change as well. While the current paradigm provides greater ecological validity than management of expression while viewing photographs, we can continue to move research forward by examining expression during interpersonal interaction. Capturing expression during interaction presents a new set of challenges (e.g., creating a realistic scenario, capturing 
changes in movement, lighting, etc.), understanding the role of culture on behavioral management within the interpersonal context should be the next goal.

Future research could add cognitive load to the paradigm by not only adding an interactive component, but a task of faking felt emotion as well. This relates more closely to real life, as we rarely need to passively sit back and express neutrality-the management of face within interpersonal communication involves strategic management of behavior as well as a persona. Differences in emotion expressivity and ability to suppress may affect the ability to communicate effectively with potential friends, colleagues, and romantic partners. This has greater implications for the growing number of interethnic relationships that characterize diverse nations like Singapore and the United States.

While these results provide insight into intra-cultural diversity, the limitations of this data must be acknowledged. First, we only examined two emotional expressions - happiness and disgust - which represent only a fraction of the possible nonverbal indicators that are displayed both naturally and under emotionally charged conditions. While our clips were intended to elicit disgust and happiness, it is possible that other emotions were elicited instead. Additional work is needed to examine the full range of emotional expressions displayed during the video task and any differences in individual emotional displays.

While these video clips were chosen with the sample in mind, it is also possible that they did not arouse emotion in all participants. Another explanation for the fewer disgust expressions shown by the Chinese participants could be that the videos did not elicit disgust in these participants. We intentionally did not ask for self-report of emotion or verify emotional experience using independent measures, in order to remain as un-invasive and capture as natural of expression as possible. While it is possible that differences among cultural groups does not represent a difference in suppression but rather a difference in felt emotion, we think this is unlikely as our pre-test sample also included Chinese participants whom rated the chosen video clips as highly "disgusting".

We allowed participants in the control condition to express naturally as if they were "at home and relaxed" and this limited our ability to fully analyze some participants. We removed several participants from the analysis due to facial occlusions due to their body movements up, down, out of frame, or covering their face. Participants did not receive any instruction on their body posture and positioning, and a few participants-usually the control participants during the disgust-eliciting video clips-moved out of the screen. This may bias our results as we cannot be certain that participants who turned away from the camera or covered their faces showed the same facial behaviors as the rest of the sample. Their movements to hide their behaviors by covering their face or turning away may even suggest they felt more intense emotions and held less emotional control than the included participants.

\section{Conclusion}

Overall, results suggest that while individuals from Asian and collectivistic cultures engage in routine expression management, there are differences in expression and suppressive capacity within this one small, Asian nation. Differences were uncovered based on ethnic grouping, which may reflect the differences in the values affecting emotional display. From a broader perspective, future research involving multiple Asian ethnicities could refrain from grouping Asian ethnicities under a single category to improve accuracy of results. However, additional study is required to identify and confirm the social and personal markers that affect our ability to manage emotional expression within and across cultures.

\section{References}

Ackermann, A. (1997). They give us the categories and we fill ourselves in: Ethnic thinking in Singapore. International Journal on Minority and Group Rights, 4, 451-467. http://dx.doi.org/10.1163/15718119620907283

Baldwin, J. R., Faulkner, S. L., Hecht, M. L., \& Lindsley, S. L. (2006). Redefining culture: Perspectives across the disciplines. Mahwah, NJ: Lawrence Erlbaum Associates.

Butler, E. A., Lee, T. L., \& Gross, J. J. (2007). Emotion regulation and culture: Are the social consequences of emotion suppression culture-specific? Emotion, 7(1), 30-48. http://dx.doi.org/10.1037/1528-3542.7.1.30

Cai, D. A., \& Fink, E. L. (2002). Conflict style differences between individualists and collectivists. Communication Monographs, 69, 67-87. http://dx.doi.org/10.1080/03637750216536

Chan, Y. W., Haines, H., \& Lee, J. (2014). The Age of Asian Migration: Continuity, Diversity, and Susceptibility (Vol. 1). Newcastle upon-Tyne: Cambridge Scholars Publishing. 
Chang, W. C., Wong, W. K., \& Koh, J. B. K. (2003). Chinese values in Singapore: Traditional and modern. Asian Journal of Social Psychology, 6(1), 5-29. http://dx.doi.org/10.1111/1467-839X.t01-1-00007

Chen, X., \& Swartzman, L. C. (2001). Health beliefs and experiences in Asian cultures. In S. S. Kazarian, \& D. R. Evans (Eds.), Handbook of cultural health psychology (pp. 389-410). San Diego, CA: Academic Press. http://dx.doi.org/10.1016/B978-012402771-8/50016-7

Chua, B. H. (2009). Being Chinese under official multiculturalism in Singapore. Asian Ethnicity, 20(3), 239-250.

Clammer, J. (1985). Singapore: Ideology, Society, Culture. Singapore: Chopmen.

Ekman, P. (1977). Biological and cultural contributions to body and facial movement. In J. Blacking (Ed.), Anthropology of the body (pp. 34-84). London: Academic Press.

Ekman, P. (2003). Emotions Revealed: Recognizing Faces and Feelings to Improve Communication and Emotional Life. New York: Henry Holt \& Co.

Ekman, P., \& Friesen, W. V. (1969). The repertoire of nonverbal behavior: Categories, origins, usage, and coding. Semiotica, 1, 49-98. http://dx.doi.org/10.1515/semi.1969.1.1.49

Ekman, P., \& Friesen, W. V. (1971). Constants across cultures in the face and emotion. Journal of Personality and Social Psychology, 17, 124-129. http://dx.doi.org/10.1037/h0030377

Ekman, P., \& Friesen, W. V. (1975). Unmasking the face: A guide to recognizing the emotions from facial cues. Englewood Cliffs, NJ: Prentice Hall.

Ekman, P., Irwin, W., \& Rosenberg, E. (1994). Emotional Facial Action Coding System (EMFACS-8) (Unpublished manuscript). University of California at San Francisco.

Ekman, P., Sorenson, E. R., \& Friesen, W. V. (1969). Pancultural elements in facial displays of emotion. Science, 164, 86-88. http://dx.doi.org/10.1126/science.164.3875.86

Fletcher, C. V., Nakazawa, M., Chen, Y., Oetzel, J. G., Ting-Toomey, S., Chang, S., \& Zhang, Q. (2014). Establishing cross-cultural measurement equivalence of scales associated with face-negotiation theory: A critical issue in cross-cultural comparisons. Journal of International and Intercultural Communication, 7(2), 148-169. http://dx.doi.org/10.1080/17513057.2014.898364

Franchow, E. I., \& Suchy, Y. (2015). Naturally-occurring expressive suppression in daily life depletes executive functioning. Emotion, 15(1), 78-89. http://dx.doi.org/10.1037/emo0000013

Frijda, N. H. (1986). The emotions. London, England: Cambridge University Press.

Galovan, A. M., Fackrell, T., Buswell, L., Jones, B. L., Hill, E. J., \& Carroll, S. J. (2010). The work-family interface in the United States and Singapore: Conflict across culture. Journal of Family Psychology, 24(5), 646-656. http://dx.doi.org/10.1037/a0020832

Goffman, E. (1959). The presentation of self in everyday life. Garden City, NY: Double Day.

Gross, J. J. (1998). The emerging field of emotion regulation: An integrative review. Review of General Psychology, 2, 271-299. http://dx.doi.org/10.1037/1089-2680.2.3.271

Gross, J. J. (2002). Emotion regulation: Affective, cognitive, and social consequences. Psychophysiology, 39, 281-291. http://dx.doi.org/10.1017/S0048577201393198

Gross, J. J., \& John, O. P. (2003). Individual differences in two emotion regulation processes: Implications for affect, relationships, and well-being. Journal of Personality and Social Psychology, 85, 348-362. http://dx.doi.org/10.1037/0022-3514.85.2.348

Gross, J., \& Levenson, R. W. (1993). Emotional suppression; Physiology, self-report, and expressive behavior. Journal of Personality and Social Psychology, 64(6), 970-986. http://dx.doi.org/10.1037/0022-3514.64.6.970

Hofstede, G. (1980). Culture's consequences: International differences in work-related values. Beverly Hills, CA: Sage.

Hui, C. H., \& Triandis, H. C. (1986). Individualism-collectivism: A study of cross-cultural researchers. Journal of Cross-cultural Psychology, 17, 225-248. http://dx.doi.org/10.1177/0022002186017002006

Hurley, C. M., \& Frank, M. G. (2011). Executing facial control during deception situations. Journal of Nonverbal Behavior, 35, 119-131. http://dx.doi.org/10.1007/s10919-010-0102-1 
Kirkman, B. L., Lowe, K. B., \& Gibson, C. B. (2006). A quarter century of culture's consequences: A review of empirical research incorporating Hofstede's cultural values framework. Journal of International Business Studies, 37, 285-320. http://dx.doi.org/10.1057/palgrave.jibs.8400202

Lang, P. J., Bradley, M. M., \& Cuthbert, B. N. (1999). International Affective Picture System: Technical manual and affective ratings. Gainesville, FL: The Center for Research in Psychophysiology, University of Florida.

Lebowitz, M. S., \& Dovidio, J. F. (2015). Implications of emotion regulation strategies for empathetic concern, social attitudes, and helping behavior. Emotion, 15, 187-194. http://dx.doi.org/10.1037/a0038820

Louie, J. Y., Oh, B. J., \& Lau, A. S. (2013). Cultural differences in the links between parental control and children's emotional expressivity. Cultural Diversity and Ethnic Minority Psychology, 19, 424-434. http://dx.doi.org/10.1037/a0032820

Mak, K., Ho, C. H., Chua, V., \& Ho, R. M. (2015). Ethnic differences in suicide behavior in Singapore. Transcultural Psychiatry, 52(1), 3-17. http://dx.doi.org/10.1177/1363461514543545

Mariapun, S., Li, J., Yip, C. H., Taib, N. M., \& Teo, S. (2015). Ethnic differences in mammographic densities: An Asian cross-sectional study. Plos One, 10(2), e0117568. http://dx.doi.org/10.1371/journal.pone.0117568

Markus, H. R., \& Kitayama, S. (1991). Culture and the self: Implications for cognition, emotion, and motivation. Psychological Review, 98, 224-253. http://dx.doi.org/10.1037/0033-295X.98.2.224

Matsumoto, D., Takeuchi, S., Andayani, S., Kouznetsova, N., \& Krupp, D. (1998). The contribution of individualism vs. collectivism to cross-national differences in display rules. Journal of Social Psychology, 1, 147-165. http://dx.doi.org/10.1111/1467-839x.00010

Matsumoto, D. et al. (2008). Culture, emotion regulation, and adjustment. Journal of Personality and Social Psychology, 94, 925-937. http://dx.doi.org/10.1037/0022-3514.94.6.925

Meihlke, A. (1973). Surgery of the facial nerve. Philadelphia: Saunders.

Ministry of Culture, Community and Youth. (2015). About us. Retrieved from http://www.mccy.gov.sg/en/About-us.aspx

Ministry of Education. (2014). Racial harmony day celebrations 2014 "harmony from the heart" [Press release]. Retrieved from http://www.moe.gov.sg/media/press/2014/07/racial-harmony-day-celebration2014-harmony-of-the-heart.php

Murata, A., Moser, J. S., \& Kitayama, S. (2013). Culture shapes electrocortical responses during emotion suppression. Scan, 8, 595-601. http://dx.doi.org/10.1093/scan/nss036

Myers, R. E. (1976). Comparative neurology of vocalization of speech: Proof of a dichotomy. Annual Review of the New York Academy of Sciences, 280, 745-757. http://dx.doi.org/10.1111/j.1749-6632.1976.tb25537.x

Ng, T. P., Leong, T., Chiam, P. C., \& Kua, E. (2010). Ethnic variations in dementia: The contributions of cardiovascular, psychosocial and neuropsychological factors. Dementia and Geriatric Cognitive Disorders, 29(2), 131-138. http://dx.doi.org/10.1159/000275668

Oetzel, J. G., \& Ting-Toomey, S. (2003). Face concerns in interpersonal conflict: A cross-cultural empirical test of the face negotiation theory. Communication Research, 30, 599-624. http://dx.doi.org/10.1177/0093650203257841

Parliament Debates: Official Report. (1989, February 16). Better racial mix in HDB housing estates (Vol. 52, pp. 650-651).

Porter, S., \& Ten Brinke, L. (2008). Reading between the lies: Identifying concealed and falsified emotions in $\begin{array}{lllll}\text { universal facial expressions. Psychological } & \text { Science, }\end{array}$ http://dx.doi.org/10.1111/j.1467-9280.2008.02116.x

Qi, X. (2011). Face: A Chinese concept in a global sociology. Journal of Sociology, 47(3), 279-295. http://dx.doi.org/10.1177/1440783311407692

Rao, N., McHale, J. P., \& Pearson, E. (2003). Links between socialization goals and child rearing practices in Chinese and Indian mothers. Infant and Child Development, 12(5), 475-492. http://dx.doi.org/10.1002/icd.341

Rottenberg, J., Ray, R. D., \& Gross, J. J. (2007). Emotion elicitation using films. In J. A. Coan, \& J. J. B. Allen (Eds.), Handbook of Emotion Elictiation and Assessment (pp. 9-28). New York: Oxford University Press. 
Safdar, S., Friedlmeier, W., Matsumoto, D., Yoo, S. H., Kwantes, C. T., Kakai, H., \& Shigemasu, E. (2009). Variations of emotional display rules within and across cultures: A comparison between Canada, USA, and Japan. Canadian Journal of Behavioural Science, 41(1), 1-10. http://dx.doi.org/10.1037/a0014387

Schmeichel, B. J., Volokhov, R. N., \& Demaree, H. A. (2008). Working memory capacity and the self-regulation of emotional expression and experience. Journal of Personality and Social Psychology, 95, 1526-1540. http://dx.doi.org/10.1037/a0013345

Siddique, S. (1989). Singaporean identity. In K. S. Sandhu, \& P. Wheatley (Eds.), The moulding of modern Singapore (pp. 563-577). Singapore: Institute of Southeast Asian Studies.

Singapore Department of Statistics. (2015). Monthly Digest of Singapore Statistics. Retrieved from http://www.singstat.gov.sg/publications/publications-and-papers/reference/monthly-digest-of-statistics

Soto, J. A., Perez, C. R., Kim, Y. H., Lee, E. A., \& Minnick, M. R. (2011). Is Expressive Suppression Always Associated With Poorer Psychological Functioning? A Cross-Cultural Comparison Between European Americans and Hong Kong Chinese. Emotion, 11(6), 1450-1455. http://dx.doi.org/10.1037/a0023340

Ting-Toomey, S. (1988). Intercultural conflict styles: A face-negotiation theory. In Y. Y. Kim, \& W. B. Gudykunst (Eds.), Theories in intercultural communication (pp. 213-235). Thousand Oaks, CA: Sage Publications.

Ting-Toomey, S. (2010). Applying dimensional values in understanding intercultural communication. Communication Monographs, 77, 169-180. http://dx.doi.org/10.1080/03637751003790428

Ting-Toomey, S., \& Kurogi, A. (1998). Facework competence in intercultural conflict: An updated face-negotiation theory. International Journal of Intercultural Relations, 22, 187-225. http://dx.doi.org/10.1016/S0147-1767(98)00004-2

Tsai, J. L., Knutson, B., \& Fung, H. H. (2006). Cultural variation in affect valuation. Journal of Personality and Social Psychology, 90, 288-307. http://dx.doi.org/10.1037/0022-3514.90.2.288

Tschiassny, K. (1953). Eight syndromes of facial paralysis and their significance in locating the lesion. Annual Review of Otology, Rhinology, and Laryngology, 62, 677-691. http://dx.doi.org/10.1177/000348945306200306

Wei, M., Su, J. C., Carrera, S., \& Lin, S. (2013). Suppression and interpersonal harmony: A cross-cultural comparison between Chinese and European Americans. Journal of Counseling Psychology, 60(4), 625-633. http://dx.doi.org/10.1037/a0033413

\section{Note}

Note 1 . The subjects were removed due to facial occlusions during the majority of the critical frames, preventing facial analyses. Additional subjects were excluded in a portion of the subsequent analyses as some sections of their recording also experienced facial occlusions.

\section{Appendix A}

\section{Emotion Eliciting Video Clips Used in Current Study}

\begin{tabular}{|c|c|c|}
\hline Video Clip Name & Description (Length) & Target Emotion Triggered $\left(M^{l}\right)$ \\
\hline 1. Grandma Gets Puppy & $\begin{array}{l}\text { YouTube clip of a grandmother receiving a puppy } \\
\text { for Christmas. }(0: 48)\end{array}$ & Happy (8.79), Surprise (4.59) \\
\hline $\begin{array}{l}\text { 2. Singapore Kid Yells at } \\
\text { Teacher }\end{array}$ & $\begin{array}{l}\text { YouTube clip of Singaporean secondary student } \\
\text { yelling at his teacher. }(1: 43)\end{array}$ & $\begin{array}{l}\text { Anger (7.03), Contempt (2.62), } \\
\text { Disgust (7.66), Surprise (4.14) }\end{array}$ \\
\hline $\begin{array}{l}\text { 3. The Haunting in CT2 } \\
\text { Trailer }\end{array}$ & $\begin{array}{l}\text { Movie Trailer of a thriller movie, the Haunting. } \\
(1: 43)\end{array}$ & Fear (7.41), Surprise (2.90) \\
\hline 4. Baboon Eating Gazelle & $\begin{array}{l}\text { Earthtouch news network clip of a Baboon eating } \\
\text { a [still living] gazelle. (1:05) }\end{array}$ & Disgust (8.38), Sad (6.45) \\
\hline $\begin{array}{l}\text { 5. Surprise Reunion with } \\
\text { Mom }\end{array}$ & $\begin{array}{l}\text { Local news clip of an active duty army mother } \\
\text { reunited with son after } 10 \text { months. }(1: 36)\end{array}$ & Нарpy (8.49) \\
\hline
\end{tabular}


6. Paranormal Activity 3 Movie Trailer of a thriller movie, Paranormal Activity 3. (1:45)

\section{Fear Factor}

8. North Korea Documentary

9. Friends

10. First Aid Ad

\section{Clip from the TV Show Fear Factor, showing a contestant eating fish guts. (2:10)}

Clip from documentary: "Han, the price of freedom", which shows abuse of North Korean woman. (1:13)

Clip from TV show Friends that shows the group joking around at the coffee house. (1:06)

PSA promoting first aid, which portrays a cancer patient who recovers but then dies from choking. (2:02)

11. Puppies YouTube clip of puppies playing. (2:43)

Fear (6.11), Surprise (2.22)

Disgust (7.22)

Anger (6.67), Contempt (2.56), Disgust (6.11)

Happy (6.50)

$\operatorname{Sad}(8.41)$

Happy (8.06)

Note. Bolded clips were used in the current analyses. ${ }^{1}$ Mean score achieved on a Likert scale (with $0=n o$ felt emotion and $10=$ strongly felt emotion) for target emotion.

\section{Copyrights}

Copyright for this article is retained by the author(s), with first publication rights granted to the journal.

This is an open-access article distributed under the terms and conditions of the Creative Commons Attribution license (http://creativecommons.org/licenses/by/3.0/). 